means of studying blood distribution during various mental circumstances as was suggested by Mosso. Further, the position of the subject upon the balance has in no circumstances any effect upon the direction of the deflection produced, as was suggested by Weber. Finally, it is demonstrated that certain fairly definite mental states are accompanied by characteristic combinations of shift of the centre of gravity of the subject upon the balance. This shift is evidenced by the movements of the apparatus. The most characteristic of these is the movement towards the left side and head end during periods of relaxation, and towards the right side and foot during periods of purposeful mental activity.

C. S. R.

[117] A contribution to the study of slips of the tongue.--Ludwig EidelberG. Internat. Jour. of Psycho-analysis, 1936, 17, 462.

ANalytic investigation shows that, in studying slips of the tongue, it is important to examine the hitherto neglected 'intention interfered with,' because it has not only a conscious, harmless, but an unconscious, prohibited, significance. In other parapraxes, especially in the case of forgetting, Freud has already discussed the significance of the 'intention interfered with.'

The mechanism of slips of the tongue is as follows: a phrase or word which was to have been pronounced has not only a conscious, but an unconscious significance, the latter representing the gratification of infantile, instinctual wishes. These emanate from the id and the unconscious part of the ego sets up a defence to prevent their being satisfied. This defence is a twofold process : $(a)$ the instinct-fusion which is pressing for gratification is turned against the self, and $(b)$ the opposite of instinct-fusion is mobilized. In the present state of knowledge it is impossible to determine whether this mechanism comes into play in all slips of the tongue or only in a particular group of them.

C. S. R.

\title{
NEUROSES AND PSYCHONEUROSES
}

[118] The attitude of psychoneurotics towards death.-Walter Bromberg and Paul Schilder. The Psychoanalytic Review, 1936, 23, 1.

THE conception of death in anxiety and hysteria cases is dominated by the idea that death is the separation from a love-object. The beloved person is an unconscious incestuous object. Basically death may mean reunion with such an object. The anxiety is partly a defence against the incestuous danger, partly due to the libidinous conflict. The fundamental psychopathological formulation of the hysteriform group as regards death is that of struggle against libidinous tendencies which are interfered with by spacial separation. 
In angina and pseudo-angina cases death is again removal from the beloved person. In children that were studied cruel and sadistic attitudes expressed themselves in connexion with the fear of death. There was the fear that violence will be inflicted by an unrelenting force. Obsessional death fear is the expression of sadomasochistic attitudes towards the love object. Where the aggression is chiefly external, the idea of one's own death does not come into the foreground. Where the super-ego directs more and more aggression towards the ego, the fear concerning one's own death becomes obsessional. This may be compensated for by metaphysical speculation on an eternal life. Where the aggression of the ego becomes overwhelming, death becomes eternal punishment. In depressive cases the idea of eternal destruction is paramount. It is eternal destruction in time. In schizophrenia the belief in an eternal magic substance can be the expression of an extreme narcissistic gratification. Neither neurosis nor psychosis produces an attitude towards death which cannot be found also in the socalled normal person.

C. S. R.

[119] Galvanic skin reflex and blood pressure reactions in the psychoneuroses. -A. P. Solomon and T. L. Fentress. Jour. Nerv. Ment. Dis., 1936, 80, 163.

THE authors have tested the galvanic skin reflexes and blood pressure in a series of different types of psychoneuroses and consider that there are correlations between the large amount of bound energy (obsessive cases), a high resistance and high absolute galvanic reactions; also between a large amount of free energy (anxiety) and low resistance and low absolute galvanic reactions.

R. G. G.

[120] Association-motor investigation of the psychoneuroses.-Clarke $H$. Barnacle, Franklin G. Ebaugh, and Frederick Lemere. Amer. Jour. Psychiat., 1935, 91, 925.

THE writers' modification of Luria's association-motor apparatus is here presented and its methods explained. Investigation was thus undertaken with 50 cases of psychoneuroses and 50 socalled ' normal' controls. Luria's method seems to be more effective in the study of emotions than other methods mentioned. It is believed that association-motor studies have a definite place in the investigation and treatment of the psychoneuroses.

C. S. R. 
[121] The psychoneuroses and neuroses.-Joseph C. Yaskin. Amer. Jour. Psychiat., 1936, 93, 107.

ONE hundred cases comprising anxiety neurosis, conversion hysteria, anxiety hysteria, compulsive reactions and neurasthenia were reviewed from the standpoint of family history, personality, precipitating causes, modes of treatment and end results. The family history was neuropathic in 44 per cent. and psychopathic in 16 per cent. of cases. The personality was neurotic in 75 per cent. and psychopathic in 2 per cent. The precipitating causes ranged from ordinary everyday emotional strain and faulty contraception, through economic, social and marital conflicts, to profound psychosexual disturbances. The modes of treatment were directed towards the relief of symptoms and eradication of causes and varied in complexity from suggestion and sedative drugs to partial analysis. Regimen and hospitalization were required in about 25 per cent. of cases. Attempts at compromise formation and partial analysis were probably the most effective methods of influencing ætiological factors, especially in anxiety hysteria and obsessive reactions. In the latter group partial analysis is the only method found to possess value. The end results of treatment compared favourably with those observed in other branches of medicine.

C. S. R.

[122] Galvanic skin reflex and Danielopolu test in psychoneurotic patients.T. L. Fentress and A. P. Solomon. Arch. of Neurol. and Psychiat., 1936, 35, 770.

IN 33 psychoneurotic patients no correlation was found between the galvanic skin reflex and the sympathetic or parasympathetic activity as determined by the Danielopolu tests, the latter being a test of autonomic activity determined by the intravenous injection of atropine sulphate. Sixty-one per cent. of the patients showed increased sympathetic activity, while the vagal activity was evenly divided between high, low and normal. The high percentage showing increased sympathetic activity is believed to be explained by the tendency of the sympathetic division to discharge as a unit in contrast to the more limited activity of the parasympathetic system.

R. M. S.

[123] Emotional factors in the atiology of stammering.-MAURICE $H$. Krout. Jour. Abnorm. Soc. Psychol., 1936, 31, 174.

THIs study is based on an unselected group of stammerers of 18-21 years of age and having I.Q's. well within the range of normality. The writer concludes that: (1) Certain deep-seated emotional conflicts have an ætiological 
bearing on stammering. (2) Because these conflicts persist and the individual continues to be unable to solve them, stammering must be regarded as a major type of neurosis. (3) Since the origin of the symptoms seem to lie in early fixation on the oral and anal levels, the neurosis must be regarded as a pregenital development on which certain more or less normal conflicts of later life become grafted. (4) Hypnoanalysis, being an unconscious manipulation technique, effects but proximate changes of behaviour, leaving recovered material, in an ultimate sense, unassimilated. (5) Active analysis, even when long-continued, warps the transference situation, and thus achieves but partial success in the treatment of stammering. (6) The procedure found to be most effective-from the point of view of symptom removal-is that of passive analysis, relying on transference as its major aid.

C. S. R.

\section{PSYCHOSES}

[124] Research on the culture of tubercle bacilli in the blood and cerebrospinal fluid of dementia præcox cases (Sulla ricerca culturale del bacillo tubercolare nel sangue e nel liquido cefalo-rachidiano di malati di demenza precoce).--E. Broggi and E. Costanti. Riv. di pat. nerv. e ment., 1936, 47, 526.

AfTER rapidly reviewing the literature relating to the connexion between tuberculosis and dementia præcox, the authors draw attention to the experiments of Lowenstein on the culture of tubercular bacilli in the fluids of dementia præcox cases. Their own experiments on this latter subject, carried on under many different conditions, were uniformly negative. They discuss the fallacies of the conclusions which have been drawn and express the opinion that there is no basis for the proposition founded on this work as to the relationship between tuberculosis and mental diseases, especially dementia præcox.

R. G. G.

[125] A comparison of the weights of brain, liver, heart, spleen and kidneys of epileptic and schizophrenic patients.-Amer. Jour. Psychiat., 1936, 92, 1439.

THE weights of these organs were recorded in 143 epileptics, 284 schizophrenics and 194 patients dying in a general hospital. The average weight did not differ significantly in the epileptic and schizophrenic groups. In particular, brains of epileptics were not heavier, nor were the hearts of schizophrenics lighter, than in the other group.

C. S. R. 